\title{
PARTISIPASI MASYARAKAT DALAM MENINGKATKAN GOOD GOVERNANCE
}

\author{
Muhammad Awalil Resky S. \\ Prodi Ilmu Pemerintahan. Fakultas Ilmu Sosial dan Ilmu Politik. \\ Universitas Muhammadiyah Sidenreng Rappang. \\ Email: awali1398@gmail.com
}

\begin{abstract}
Abstrak
Partisipasi masyarakat dalam penyelenggaraan good governance adalah bagaimana masyarakat mengambil bagian atau ikut serta dalam penyelenggaraan good governance itu sendiri. Dewasa ini banyak masyarakat yang sudah sadar akan pentingnya perhatian masyarakat kepada para penyelenggara good governance yakni pemerintah agar pelaksanaan penyelenggaraan pembangunan yang solid dan bertanggung jawab dapat berjalan sesuai dengan prinsip demokrasi, sesuai dengan tujuan awal yang memang seharusnya para pelaku dalam pemerintahan melaksanakanya. Partisipasi masyarakat dalam penyelenggaraan good governance dapat berupa partisipasi masyarakat dengan menggunakan hak nya dalam menyampaikan pendapat pada proses pengambilan keputusan yang menyangkut kepentingan masyarakat, baik secara langsung maupun tidak langsung.
\end{abstract}




\section{PENDAHULUAN}

Good governance adalah suatu bentuk manajemen pembangunan, yang juga disebut disebut sebagai administrasi pembangunan. Pada dasarnya, penerapan tata pemerintahan yang baik merupakan pelayan publik yang lebih baik kepada masyarakat, maka dari itu good governance ini sangat penting di terapkan di Kecamatan Baranti Kabupaten Sidenreng Rappang. Manajemen pembangunan atau administrasi pembangunan menempatkan peran pemerintah sentral. Maka pemerintah menjadi (agen perubahan), dari suatu masyarakat (developing) dalam negara berkembang, khususnya pada wilayah daerah.(Sulaeman, Mustanir, and Muchtar 2019).

Good governance pada pencapaiannya wajib didukung sang public service menjadi orientasi pada penyelenggaraan pelayanan. Pelayanan publik sebagai bagian krusial pada pencapaian tujuan pemerintahan yang baik. (Jamal, Mustanir, and Latif 2020)

Penerapan prinsip-prinsip good governance sangat penting dalam pelaksanaan pelayanan publik untuk meningkatkan kinerja aparatur negara. Hal ini karena pemerintah merancang konsep prinsip-prinsip good governance untuk meningkatkan potensi perubahan dalam birokrasi agar mewujudkan pelayanan publik yang lebih baik. (Cahyadi 2017)

\section{Kajian Teori}

\section{Konsep Partisipasi dan Partisipasi Masyarakat Partisipasi}

Partisipasi anggota masyarakat merupakan keterlibatan anggota masyarakat dalam pembangunan, meliputi kegiatan dalam perencanaan dan pelaksanaan (implementasi) program/proyek pembangunan yang dikerjakan di 
dalam masyarakat 2 . Sedangkan Partisipasi masyarakat dalam pembangunan diartikan ikut sertanya masyarakat dalam pembangunan, ikut dalam kegiatan pembangunan dan ikut serta pemanfaatan dan menikmati hasil pembangunan.(Mustanir and Abadi 2017)

Berdasarkan hal tersebut maka partisipasi masyarakat adalah suatu aktivitas yang mengikutsertakan perasaan dan emosional seseorang dalam proses pembuatan keputusan dan melaksanakan tanggung jawab dalam suatu organisasi atau kelompok dalam mencapai tujuan bersama yang telah ditetapkan.

Bornby dalam (Mardikanto \& Poerwoko, 2015) (Mustanir and Yasin 2018) misalnya, mengartikan partisipasi sebagai tindakan untuk "mengambil bagian" yaitu kegiatan atau pernyataan untuk mengambil bagian dari kegiatan dengan maksud memperoleh manfaat. Partisipasi adalah keikutsertaan seseorang atau sekelompok anggota masyarakat dalam suatu kegiatan (Mardikanto \& Poerwoko, 2015). Sedangkan Verhangen dalam (Mardikanto \& Poerwoko, 2015) (Irwan et al. 2019) menyatakan bahwa partisipasi merupakan suatu bentuk khusus dari interaksi dan komunikasi yang berkaitan dengan pembangian kewenangan, tanggung jawab, dan manfaat.(Mustanir, Fitriani, et al. 2020)

According to [1], Participation of community members is the involvement of community members in development include activities in the planning and execution (implementation) of program / project development performed in the community. Meanwhile, according to [2], Community participation in development is defined as community participation in the development, participation in development activities and participation in utilizing and enjoying the results of the development. Study on the definition of community participation [3] addressed the scope of participation by starting with the sequence of the development planning process, the type of community participation in development as follows: 1) 
Participation in decision-making, 2) participation in the implementation of activities, 3) participation in the monitoring and evaluation of development,. (Mustanir, Abadi, and A. 2017)

\section{Konsep Dasar Good Governance}

Pemerintah atau "Government" dalam bahasa inggris dapat diartikan sebagai "The governing body of nation, state, city, etc." Sedangkan istilah "kepemerintahan" atau dalam bahasa inggris "governance" yaitu "the act, fact, manner of governing", yaitu yang berarti "tindakan, fakta, pola, dan sikap atau kegiatan penyelenggaraan pemerintahan”. Dengan demikian governance adalah suatu kegiatan atau proses, sebagaimana diungkapkan dengan Kooiman (Sedarmayanti 2012:2) bahwa governance lebih merupakan suatu rangkaian proses dari interaksi sosial poltik antara pemerintahan dengan masyarakat dalam berbagai bidang yang berkaitan dengan kepentingan masyarakatv dan interfensi pemerintah atas kepentingan-kepentingan tersebut.(Nurimansyah et al. 2020)

United Nations Development Program (UNDP) (Kasemin 2015:33) good governance yaitu "the exercise of political, economic, and administrative authority to manage a nation's affair at all level's" atau jika diartikan yang berarti governance adalah suatu pelaksanaan pada aspek politik (dalam pembuatan regulasi atau kebijakan), ekonomi (dalam pembuatan keputusan akan sumber daya ekonomi), dan otoritas administratif (dalam penerapan kebijakan) dalam mengelola urusan negara, serta sebagai hubungan yang sinergis dan konstruktif antara pemerintah, masyarakat, dan pihak swasta. (Nurimansyah et al. 2020)

Menurut Mardiasmo (1999 : 18) good governance adalah suatu konsep pendekatan yang berorientasi kepada pembangunan sektor publik oleh pemerintahan 
yang baik. Negara dengan birokrasi pemerintahan dituntut untuk merubah pola pelayanan diri birokratis elitis menjadi birokrasi populis. Dimana sektor swasta sebagai pengelola sumber daya di luar negara dan birokrasi pemerintah pun harus memberikan kontribusi dalam usaha pengelolaan sumber daya yang ada. Penerapan cita good governance pada akhirnya mensyaratkan keterlibatan organisasi masyarakatnya sebagai kekuatan penyeimbang negara. (Cahyadi 2017)

A leader is an important thing in organizing the needs of the community in their region.

The leader also has a role to provide direction and give real influence on the subordinates or employees in carrying out the functions of an agency. Leadership is the ability to influence a group towards the achievement of the goal. The bureaucracy is an important instrument in modern society, its existence is not inevitable as a logical consequence of the main task of the government to carry out public welfare (social welfare) as in the public service. quality Service is one manifestation of the implementation of the principles of good governance.(Mustanir, Jermsittiparsert, et al. 2020)

\section{Prinsip - prinsip Good Governance}

Menurut UNDP (United Nation Development Program) mengemukakan bahwa karakteristik atau prinsip-prinsip yang dikembangkan dalam pemerintahan yang baik (good governance) adalah sebagai berikut (Mulyawan, 2009: 20-23) (Nurimansyah et al. 2020)

a. Partisipasi Setiap orang atau warga negara harus memiliki hak suara yang sama dalam proses pengambilan keputusan sesuai dengan kepentingan dan aspirasinya masing-masing. 
b. Aturan Hukum (Rule of Law) Kerangka aturan hukum dan perundang-undangan haruslah berkeadilan, ditegakkan dan dipatuhi secara utuh terutama aturan hukum tentang hak asasi manusia

\section{c. Transparansi}

Transparansi harus dibangun dalam kerangka kebebasan aliran informasi berbagai proses, kelembagaan, dan informasi harus dapat diakses secara bebas oleh orangorang yang membutuhkannya, serta informasi harus dapat disediakan secara memadai dan mudah dimengerti sehingga dapat digunakan sebagai alat monitoring dan evaluasi.

d. Daya tanggap (Responsivenes) Setiap institusi dan prosesnya harus diarahkan pada upaya untuk melayani berbagai pihak yang berkepentingan (stakeholders).

e. Berorientasi Konsensus (Consensus Orientation) Pemerintah yang baik (good governance) akan bertindak sebagai penengah (mediator) bagi berbagai kepentingan yang berbeda untuk mencapai kesepakatan yang terbaik bagi kepentingan masingmasing pihak.

f. Berkeadilan (Equity) Pemerintahan yang baik akan memberikan kesempatan yang sama baik terhadap laki-laki maupun prempuan dalam upaya mereka untuk

g. Efektifitas dan Efisiensi Setiap proses dan kelembagaan diarahkan untuk menghasilkan sesuatu yg benar-benar sesuai dengan kebutuhan melalui pemanfaatan yang sebaik-baiknya dari berbagai sumber yang tersedia.

h. Akuntabilitas Para pengambil keputusan (decision makers) dalam organisasi sektor pelayanan, dan warga negara madani memiliki pertanggungjawaban (akuntanbilitas) kepada publik (masyarakat umum) sebagaimana halnya kepada para pemilik 
(stakeholders). Pertanggung jawaban tersebut berbeda-beda, tergantung pada jenis keputusan organisasi itu bersifat internal atau bersifat eksternal.

\section{i. Bervisi Strategis Para}

Para pemimpin dan warga negara memiliki perspektif yang luas dan jangka panjang tentang penyelenggaraan pemerintahan yang baik (good governance) dalam hal pembangunan manusia, bersamaan dengan dirasakannya kebutuhan untuk pembangunan tersebut. Mereka juga memahami aspek-aspek historis, kultur, dan kompleksitas sosial yang mendasari perspektif mereka.

j. Saling Keterkaitan

Bahwa keseluruhan ciri good governance tersebut di atas adalah saling memperkuat dan saling terkait dan tidak berdiri sendiri.

Membicarakan masalah orientasi subyek yang murni yang seiring wujud di dalam masyarakat dimana tidak terdapat struktur input yang di diferensiasikan. Orientasi subyek dalam sistem politik yang telah mengembangkan pranata-pranata demokrasi lebih bersifat afektif dan normatif dari pada kognitif.(Mustanir and Jaya 2016)

Asep Supriatna (2014 :43) menyebutkan dalam pendekatan Participatory Rural Appraisal

(PRA), penelusuran lokasi (transect) sangat penting untuk melakukan pengamatan langsung terhadap lingkungan dan sumberdaya masyarakat, dengan cara melakukan perjalanan bersama menelusuri wilayah desa. Melakukan transect diawali dari lokasi dengan titik dengan ketinggian terendah menuju ke titik tertinggi di desa yang diamati atau disesuaikan dengan kesepakatan warga masyarakat. Hasil penelusuran lokasi selanjutnya dituangkan ke dalam sebuah bagan yang disebut Bagan Transect yang berupa gambar irisan lahan yang dilalui, sekaligus menggambarkan ketinggian lokasi dan aktivitas perekonomian masyarakat pada berbagai ketinggian tersebut. Data-data yang dicatat antara lain: ketinggian lokasi, sumber daya alam, obkek-objek 
penting, permasalahan yang dihadapi masyarakat dan lingkungan, kondisi teknis, sosial, dan perekonomian masyarakat, keadaan sarana dan prasarana umum dan sebagainya. (Mustanir and Yasin 2018)

Mahsun (2006: 83) juga membedakan akuntabilitas dalam arti sempit dan arti luas, akuntabilitas dalam pengertian yang sempit dapat dipahami sebagai bentuk pertanggungjawban yang mengacu pada siapa organisasi (atau pekerja individu) bertangungjawab dan untuk apa organisasi bertanggngjawab. (Muis, Saleh, and Rusli 2016)

\section{KESIMPULAN}

Good governance pada pencapaiannya wajib didukung sang public service menjadi orientasi pada penyelenggaraan pelayanan. Pelayanan publik sebagai bagian krusial pada pencapaian tujuan pemerintahan yang baik. Pemerintah membangun suasana kompetitif dalam memberikan pelayanan; Pemerintah berorientasi pada kebutuhan pasar, bukan birokrasi; Pemerintahan desentralisasi dan lebih proaktif. (Jamal, Mustanir, and Latif 2020)

Pemerintah atau "Government" dalam bahasa inggris dapat diartikan sebagai "The 
governing body of nation, state, city, etc." Sedangkan istilah "kepemerintahan" atau dalam bahasa inggris "governance" yaitu "the act, fact, manner of governing", yaitu yang berarti "tindakan, fakta, pola, dan sikap atau kegiatan penyelenggaraan pemerintahan". Dengan demikian governance adalah suatu kegiatan atau proses, sebagaimana diungkapkan dengan Kooiman (Sedarmayanti 2012:2) bahwa governance lebih merupakan suatu rangkaian proses dari interaksi sosial poltik antara pemerintahan dengan masyarakat dalam berbagai bidang yang berkaitan dengan kepentingan masyarakatv dan interfensi pemerintah atas kepentingan-kepentingan tersebut. Sedang oleh United Nations Development Program (UNDP) (Kasemin 2015:33) good governance yaitu "the exercise of political, economic, and administrative authority to manage a nation's affair at all level's" atau jika diartikan yang berarti governance adalah suatu pelaksanaan pada aspek politik (dalam pembuatan regulasi atau kebijakan), ekonomi (dalam pembuatan keputusan akan sumber daya ekonomi), dan otoritas administratif (dalam penerapan kebijakan) dalam mengelola urusan negara, serta sebagai hubungan yang sinergis dan konstruktif antara pemerintah, masyarakat, dan pihak swasta.(Nurimansyah et al. 2020)

Partispasi masyarakat merupakan suatu proses yangdapat mendukung masyarakat untuk mulai "sadar" akan situasi dan masalah yang dihadapinya serta berupaya mencari jalan keluar yangdapat dipakai untuk mengatasi masalah mereka (memiliki kesadaran kritis). Sumardi (2010:46), mengemukakan bahwa partisipasi adlah peran serta seseorang atau kelompok masyarakat dalam proses pembangunan baik dalam bentuk pernyataan maupun dalam bentuk kegiatan dengan memberi masukan pikiran, tenaga, waktu, keahlian, modal, dan atau materi, serta ikut memanfaatkan dan menikmati hasil-hasil pembangunan.(Sulaeman, Mustanir, and Muchtar 2019)

Isbandi dalam (Mustanir,Abadi, \& Nasri, 2016; Mustanir, Ali, \& Yasin, 2018; Uceng, Ali, Mustanir, \& Nirmawati, 2019; Uceng, Erfina, Mustanir, \& Sukri, 2919) 
mengatakan bahwa konsep partisipasi juga meliputi : Partisipasi mengenai hak politik, termasuk didalam pengambilam kebijakan publik, dilakukan secara sistemik, sebagai instrumen yang mendorong tata pemerintahan yang baik, serta dapat meningkatkan kepercayaan masyarakat terhadap penyelenggaraan pemerintahan. (Mustanir, Latif, and Irwan 2019)

Deliberation of development planning as a method to make the community contributing on decision making or policy related to regional development planning. Decision making is an election among several alternatives problem solving. The decision of the development plan itself cannot be separated from several factors that influence it, including dealing with the environment, which one of its most difficult characteristic in decision making is uncertainty.(Ahmad Mustanir et al. 2018) 


\section{DAFTAR PUSTAKA}

Ahmad Mustanir, Nur Justira, Kamaruddin Sellang, and Andi Ilham Muchtar. 2018.

"Democratic Model On Decision-Making At Deliberations Of Development

Planning." International Conference on Government Leadership and Social

Science (ICOGLASS). Demanding Governance Accountability and Promoting

Democratic Leadership for Public Welfare Achievement (April): 110 - 115. https://www.researchgate.net/publication/330090538_Democratic_Model_On_D ecision-Making_At_Deliberations_Of_Development_Planning.

Cahyadi, Arif. 2017. "PENERAPAN GOOD GOVERNANCE DALAM

PELAYANAN PUBLIK (Studi Tentang Kualitas Pelayanan Elektronik Kartu Tanda Penduduk Berbasis Good Governance Di Kecamatan Sukolilo Surabaya)." JPAP: Jurnal Penelitian Administrasi Publik 3(2).

Jamal, Yenni, Ahmad Mustanir, and Adam Latif. 2020. "Penerapan Prinsip Good Governance Terhadap Aparatur Desa Dalam Pelayanan Publik Di Desa CiroCiroe Kecamatan Watang Pulu Kabupaten Sidenreng Rappang." PRAJA: Jurnal Ilmiah Pemerintahan 8(3): 207-12.

Muis, Muhammad Amirul Haq, Hasrat Arief Saleh, and Andi M. Rusli. 2016. “Analisis Implementasi Good Governance Dalam Pelayanan Publik Di Kecamatan Panakukkang Kota Makassar.” Jurnal Ilmu Pemerintahan 7(2): 7382. https://media.neliti.com/media/publications/102131-ID-analisisimplementasi-good-governance-da.pdf.

Mustanir, Ahmad, S Fitriani, et al. 2020. "Sinergitas Peran Pemerintah Desa Dan Partisipasi Masyarakat Terhadap Perencanaan Pembangunan Di Kabupaten 
Sidenreng Rappang (The Synergy of Village Government's Role and Community Participation in the Process of Development Planning in Sidenreng Rappang D.” Journal of Government Science (GovSci) 2020(2): 84-108.

Mustanir, Ahmad, Kittisak Jermsittiparsert, et al. 2020. "Village Head Leadership and Bureaucratic Model Towards Good Governance in Sidenreng Rappang."

Mustanir, Ahmad, and Partisan Abadi. 2017. "Partisipasi Masyarakat Dalam Musyawarah Rencana Pembangunan Di Kelurahan Kanyuara Kecamatan Watang Sidenreng Kabupaten Sidenreng Rappang." Jurnal Politik Profetik 5(2): 247-61. http://journal.uinalauddin.ac.id/index.php/jpp/article/viewFile/4347/3986\%0Ahttp://journal.uinalauddin.ac.id/index.php/jpp/issue/view/636.

Mustanir, Ahmad, Partisan Abadi, and Nasri A. 2017. "Participation of Ethnic Community Towani Tolotang in Deliberation of Development Plan.” 84(Iconeg 2016): $356-59$.

Mustanir, Ahmad, and Irfan Jaya. 2016. "Pengaruh Kepemimpinan Dan Budaya Politik Terhadap Perilaku Pemilih Towani Tolotang Di Kecamatan Maritengngae Kabupaten Sidenreng Rappang.” Jurnal Politik Profetik 4(1): 8497. http://journal.uinalauddin.ac.id/index.php/jpp/article/view/2741\#\%0Ahttp://journal.uinalauddin.ac.id/index.php/jpp/issue/view/430.

Mustanir, Ahmad, Adam Latif, and Irwan Irwan. 2019. “Analisis Kepemimpinan Terhadap Optimalisasi Masyarakat Pada Perencanaan Pembangunan Di Enrekang.” Jurnal Analisis Kebijakan dan Pelayanan Publik (JAKPP) 5(2): 120. journal.unhas.ac.id/index.php/jakpp.

Mustanir, Ahmad, and Akhmad Yasin. 2018. "Transect Pada Perencanaan Pembangunan Partisipatif.” 8(2): 21-31. 
Nurimansyah, Muwaffiq, R Misriah Ariyani, Sulawesi Selatan, and Jawa Barat. 2020. “Implementasi Good Governance Dalam.” 2(2): 114-27.

Sulaeman, Zhilviana, Ahmad Mustanir, and Andi Ilham Muchtar. 2019. "Partisipasi Masyarakat Terhadap Perwujudan Good Governance Di Desa Damai Kecamatan Watang Sidenreng Kabupaten Sidenreng Rappang." PRAJA: Jurnal Ilmiah Pemerintahan 7(3): 88-92. 